HOT HUMID ENVIRONMENT :

\title{
ITS EFFECT ON THE PERFORMANCE OF A MOTOR CO-ORDINATION TEST
}

BY

\section{J. S. WEINER and J. C. D. HUTCHINSON}

From the Medical Research Council Neurological Research Unit, National Hospital, Queen Square, London

It is well known that prolonged stay in a hot humid environment, especially when the temperature of the body is raised, is accompanied by feelings of lassitude and irritability. In such conditions, as simulated in the laboratory, one is often aware also of a tendency to forgetfulness, to some 'slowing' of one's movements and there seems to be an enhanced liability to breakage of glassware and thermometers. Many observers of experiments in hot conditions have testified to such reactions.

During the course of some experiments on acclimatization to heat we had the opportunity of making a number of observations on the "psychomotor' performance of resting and working subjects exposed to 'effective' temperatures above $90^{\circ} \mathrm{F}^{*}$ The results presented in this paper are regarded as preliminary only and of limited application to everyday activity in hot climates or occupations. However, as the findings seem sufficiently consistent we consider they support the belief that a measureable impairment of manual dexterity or co-ordination occurs at high environmental temperatures.

\section{Experiments}

The test of motor co-ordination used throughout the experiments was one devised by the Cambridge Psychological Laboratory. The apparatus consists of a gramophone disc rotated at constant speed by an electric motor. This gramophone top is mounted at an inclination of $13^{\circ}$ to the horizontal and carries a bakelite plate provided with an inner and outer series of perforations. The task set for the subject is as follows: using a pair of forceps, and in as short a time as he is able, the subject is required to pick up from the inner circle of holes each of 84 small steel ball-bearings ( $\frac{3}{8}$ inch) and deposit these in the outer series of holes while the gramophone disc is rotating. Any balls which are not accurately placed in the holes or which slip from the forceps, run down the sloping disc into a tray from which they must be picked up until all the balls have been successfully deposited. The subject then returns the balls from the outer circle of holes to the inner, retrieving any dropped balls from the tray as before. This transfer of balls from the inner to the outer ring and back to the inner constitutes a complete ' run.' Two minutes after the completion of the first run the second run

* The 'effective temperature' of an atmosphere (Houghten, F. C. Teague, W. W., and Miller, W. E., 1926) is the temperature of a still, as the atmosphere in question. is performed, and after a rest of 15 seconds the third run is performed. The time taken to complete each run is noted by means of a stop-watch and the total test time for the three runs is thus obtained. The number of balls retrieved from the tray for each run is also noted and hence the total number of balls actually handled during each run is known. Since the time for each run is recorded, the average time taken to handle each ball can be calculated.

A preliminary series of experiments was carried out on 4 subjects, MacM, M, T, and Rh, aged between 20 and 30 years. They had three weeks practice at ordinary room temperature and then carried out the co-ordination test after two hours exposure nude in an environment of dry bulb $95^{\circ} \mathrm{F}$. and wet bulb $90^{\circ} \mathrm{F}$., air movement 30 feet per minute, giving a temperature of $91^{\circ} \mathrm{F}$. on the effective temperature scale (Houghten, Teague and Miller, 1926). These subjects were not acclimatized to a hot environment. On two of the subjects the test in the hot room was repeated on a second occasion. The rectal temperatures during these tests were scarcely raised. Control tests at ordinary room temperature (dry bulb $65^{\circ}$ to $68^{\circ} \mathrm{F}$.) were done on the same day or within a few days of the test in the hot room.

In the main series of experiments the 6 subjects, aged 25 to 35 , were well acclimatized to working in hot humid environments. The co-ordination test was carried out at dry bulb $95^{\circ} \mathrm{F}$. and wet bulb $90^{\circ} \mathrm{F}$, air movement 30 feet per minute, ' effective' temperature $91^{\circ} \mathrm{F}$. The subjects were also well practised in the co-ordination test; subjects $R, P$, $\mathrm{B}$, and $\mathrm{H}$, had performed $27,23,24$, and 20 practice runs respectively on successive days, excluding Saturdays and Sundays, before the actual tests in the hot room. The two other subjects, MacK and W carried out only 11 preliminary runs. As the effect of practice is very marked in ordinary room conditions the tests were continued in such conditions after the experiment in the hot room. This enables one to compare the performance in the hot room with the average performance in ordinary room temperature before and after the test in the hot room. The tests at high environmental temperatures were arranged as follows: the subject carried out two bouts of step climbing on a 12-inch block 24 times per minute for 10 minutes with a pause of 5 minutes in between the 10 minute bouts. The exercise raised the rectal temperature in most subjects to over $101^{\circ} \mathrm{F}$. and this temperature was maintained steadily or dropped only slowly during the next hour in the hot room. An hour after the work when the pulse rate had become steady the 
co-ordination test was performed in the manner already described. The men were allowed to dry their faces and hands of sweat before each run of the test. The clothing worn in all experiments consisted of Bush shirt (open at the neck) drill trousers, army boots and socks. Control experiments were carried out in the same chamber at temperatures similar to that of ordinary room conditions. The subjects performed the psychomotor test after carrying out the same amount of work as in the heat.

A further experiment involving a prolonged stay in the hot room was carried out on one subject, $L$, aged 32. He was unacclimatized to the heat but had carried out a series of practice tests in ordinary room conditions for ten days. During the tests in the hot room he lived nude in the hot humid environment for 13 days. During the mornings he performed the co-ordination test at an 'effective' temperature of $82^{\circ} \mathrm{F}$. He then carried out certain routine observations in connection with tests on other subjects at a temperature of dry bulb $100^{\circ} \mathrm{F}$. and wet bulb $94^{\circ} \mathrm{F}$., ' effective' temperature $95^{\circ} \mathrm{F}$. During the afternoon he carried out two hours stepclimbing and forthwith performed the co-ordination test at an 'effective' temperature of about $86^{\circ} \mathrm{F}$. This ' effective' temperature varied from day to day during the 12 days, ranging between $82^{\circ} \mathrm{F}$. and $90^{\circ} \mathrm{F}$. Thus, during the morning co-ordination test his rectal temperature was normal (average $98.7^{\circ} \mathrm{F}$.) and during the afternoon tests it was markedly raised (average $103.2^{\circ} \mathrm{F}$.) as a result of the day's exercise. He slept in an environment of ' effective' temperature $82^{\circ} \mathrm{F}$. After 13 days of this routine the subject left the hot room and then carried on with a series of control tests in ordinary room temperature for the next six days.

\section{Results}

Preliminary Tests on Resting Subjects, Single Exposure

From the figures for the total test time, given in Table 1, it can be seen that in every case there was an impairment of performance during exposure to heat. The increase in the time taken to perform the test averages 8 per cent. for the 4 subjects. Thus, exposure to a hot humid environment without any rise in rectal temperature may impair coordination of fine movements. In these preliminary tests the effect of the environment on the number of balls dropped and the speed of movement was not measured.

TABLE 1

PRELIMINARY TEST ON RESTING SUBJECTS. SINGLE EXPOSURE

\begin{tabular}{l|c|c|c|c}
\hline Subject & $\begin{array}{c}\text { Mean test time } \\
\text { in cool, secs. }\end{array}$ & $\begin{array}{c}\text { No. of } \\
\text { tests }\end{array}$ & $\begin{array}{c}\text { Mean test time } \\
\text { in heat, secs. }\end{array}$ & $\begin{array}{c}\text { No. of } \\
\text { tests }\end{array}$ \\
\cline { 2 - 4 } MacM & 960 & 2 & 987 & 1 \\
M & 889 & 4 & 963 & 2 \\
T & 1110 & 3 & 1245 & 2 \\
Rh & 834 & 3 & 897 & 1 \\
\cline { 1 - 2 } Mean & 948 & - & 1023 & - \\
\cline { 2 - 3 } & & & & \\
\hline
\end{tabular}

Mean difference in test time $=75$ secs.

Deterioration $=8$ per cent.

\section{Acclimatized Subjects, after Work, Single Exposure}

The essential information is set out in Table 2 . This records the total test time, the number of balls dropped and the speed of movement per ball, of the 6 subjects, $(a)$ in the hot room after previous muscular work in comparison with relevant performances in ordinary room temperature without performance of work, and (b) at ordinary room temperature after previous work, in comparison with the relevant series of performances without previous work.

For purposes of comparison, the series of tests with work in the hot room and the series with work in ordinary room temperature were both compared with the learning curve (tests without work in the cold) and not with one another. This was necessary because the two sets of co-ordination tests involving muscular work were carried out in the case of most of the subjects over lengths of time not falling in quite the same period of the individual learning curve.

For estimating the effect of exposure to heat, the total variance is obtained by pooling the variance of the individual observations about the mean score for the different subjects, using the ordinary room temperature only. This was necessary because only one observation was made on each subject in the hot room. For the estimation of the effect of previous muscular work on co-ordination, both series of tests in ordinary room temperature are used to obtain the pooled variance.*

\section{Total Test Time Scores}

1. There is no significant difference between the means of performance in ordinary room temperatures, whether or not exercise was carried out prior to the psychomotor tests.

2. The total test time in the hot room was longer than that in ordinary room temperature. The probability that this difference is due to chance is very small $(P=0.01-0.001)$. The difference in the mean test time in the heat from that in ordinary room temperature was 14 per cent.

\section{Number of Balls Dropped}

Here again the effect of exposure to heat is marked $(P=0.001)$. The accuracy of the subjects in handling the balls was impaired in the hot room. The difference between the two series of experiments at ordinary room temperature was not significant.

\section{Time per Movement per Ball}

Here also the effect of exposure to heat was significant $(P=0 \cdot 02-0 \cdot 01)$. The movements of the subjects were slower in the hot room than in ordinary room temperature by 0.09 second per movement,

* 'Student's' test was used to estimate the significance of the difference between the 'grand' means shown in Table 2 . This test consists essentially in a comparison of the difference between two means with its standard deviation. To assess the probability that the difference between the means is due to chance, the value of $P$ is found from a table of $P$ and $t$ in which the number of degrees of freedom available for estimating the standard deviation is taken into account. Thus if $\mathrm{P}$ is found from the table to be $0 \cdot 01$, the probability that the observ is 1 in 100 . 


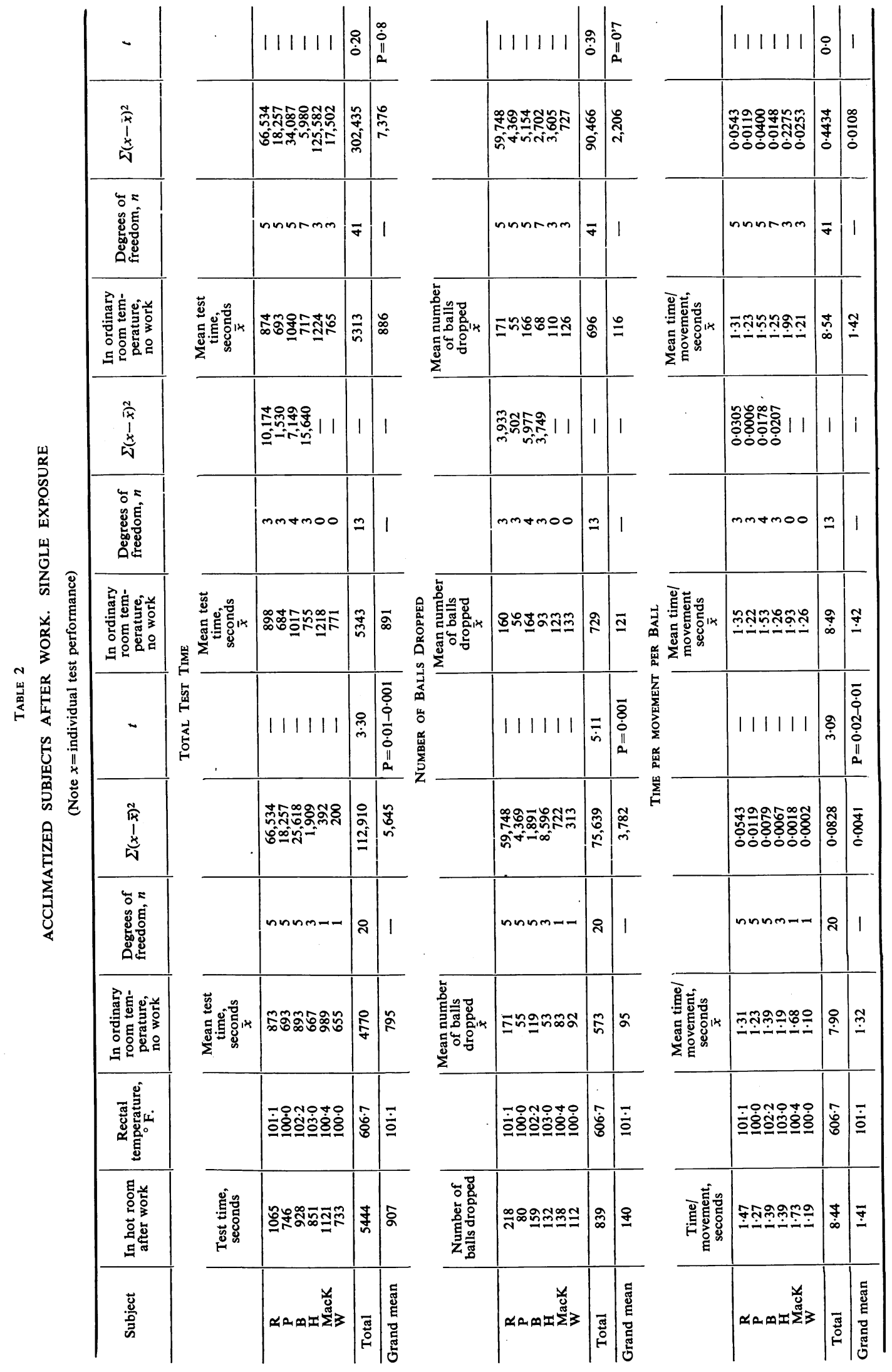


or by an average of 6 per cent.; since more balls were dropped in the hot room, part of this extra time per movement may be due to the fact that the movements to retrieve balls when dropped took longer than the other movements from one set of holes to the other. Exposure to the heat caused the subjects to revert in their performances to those given early on in their practice series, i.e. when first learning the test. In those practice tests the subjects also dropped more balls and moved more slowly than on subsequent days when improvement became noticeable.

\section{Prolonged Exposure (Subject L)}

Table 3 gives L's average performance (total test time, number of balls dropped and speed of movement) for the last four days of the practice period before going into the hot room, for the first four and the last six days in the hot room, and for six days after leaving the hot room.

TABLE 3

SUBJECT L. CONTINUED EXPOSURE TO HOT ENVIRONMENT

\begin{tabular}{|c|c|c|c|c|c|}
\hline & & $\left|\begin{array}{c}\text { cool } \\
\text { control } \\
\text { before } \\
\text { entering } \\
\text { hot room } \\
\text { last } 4 \text { days }\end{array}\right|$ & $\begin{array}{l}\text { First } \\
4 \text { days } \\
\text { in hot } \\
\text { room }\end{array}$ & $\begin{array}{l}\text { Last } \\
6 \text { days } \\
\text { in hot } \\
\text { room }\end{array}$ & $\begin{array}{l}\text { Six days } \\
\text { cool con- } \\
\text { trol after } \\
\text { being in } \\
\text { hot room }\end{array}$ \\
\hline $\begin{array}{ll}\text { Mean } & \text { total } \\
\text { test } & \text { time } \\
(\sec ) & \end{array}$ & a.m. & $\begin{array}{l}652 \\
687\end{array}$ & $\begin{array}{l}738 \\
743\end{array}$ & $\begin{array}{l}680 \\
650\end{array}$ & $\begin{array}{l}625 \\
639\end{array}$ \\
\hline $\begin{array}{ll}\text { Mear } & \text { No. } \\
\text { of } & \text { balls } \\
\text { dropped. }\end{array}$ & $\begin{array}{l}\text { a.m. } \\
\text { p.m. }\end{array}$ & $\begin{array}{l}83 \\
99\end{array}$ & $\begin{array}{l}69 \\
99\end{array}$ & $\begin{array}{l}55 \\
61\end{array}$ & $\begin{array}{l}57 \\
60\end{array}$ \\
\hline $\begin{array}{l}\text { Mean time } \\
\text { per move- } \\
\text { ment (secs.). }\end{array}$ & $\overline{\mathrm{a} . \mathrm{m} .}$ & $\begin{array}{l}1 \cdot 11 \\
1 \cdot 14\end{array}$ & $\begin{array}{l}1 \cdot 28 \\
1.23\end{array}$ & $\begin{array}{l}1 \cdot 19 \\
1.13\end{array}$ & $\begin{array}{l}1 \cdot 11 \\
1 \cdot 12\end{array}$ \\
\hline
\end{tabular}

This subject exhibited a learning curve in ordinary room temperature similar to that of the other subjects; his speed of movement became quicker on succeeding days, but he did not show any improvement as regards the number of balls dropped: his total performance time improved markedly but had become steady at the end of the practice period. On entering the hot room his performance was at first very much worse; while the number of balls dropped did not alter much, the time taken per movement was markedly increased. Consequently the total test time was longer (11 per cent.). His performance in the hot room thus reverted to that found at the beginning of the practice series in ordinary room temperature.

With further stay in the hot room the subject's performance improved rapidly until during the last six days it was practically as good as it was before he entered the hot room. This improvement was chiefly in the speed of movement but he also dropped less balls.

During the first few days in the hot room the time for completing the test was about the same in the mornings as in the afternoons although his rectal temperature was raised in the afternoons. In the final period in the hot room the total test time was actually less in the afternoon than it was in the morning, chiefly because the speed of movement was greater.

In this subject it can be seen that the exposure to the hot environment and not specifically the rise in rectal temperature had affected his performance. During the six control days after leaving the hot room L's performance was somewhat better than it $\underline{\underline{T}}$ was before the experiments in the hot room and $\bar{c}$ consequently better than his performance during $\overline{\bar{c}}$ the last few days in the hot room.

\section{Comments}

From all these experiments it appears that motor $\overrightarrow{\vec{F}}$ co-ordination is impaired in a hot humid environ- $\overline{0}$ ment. The experiments suggest that any raising of rectal temperature consequient on work in hot $\frac{\bar{p}}{\bar{\phi}}$ humid environments may not materially increase $\underset{\mathbb{Q}}{\stackrel{0}{\circ}}$ the impairment. The experiments on the subject L suggest also that 'acclimatization' of motor co- $\$$ ordination to a hot humid environment analogous $\overrightarrow{0}$ to 'acclimatization' to work takes place. How- $\overrightarrow{\vec{\omega}}$ ever, the process of this 'acclimatization' must be $\stackrel{\omega}{\sigma}$ distinct from physiological acclimatization to work ${ }_{0}$ in the hot room since the subjects $\mathrm{P}, \mathrm{R}, \mathrm{B}, \mathrm{H}, 3$ MacK, and $\mathrm{W}$, who were already acclimatized to $\stackrel{\mathrm{w}}{\mathrm{w}}$ work in the hot room nevertheless gave an impaired $\omega$ co-ordination performance in the hot room.

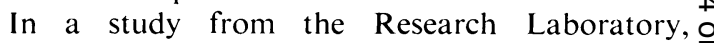
American Society of Heating and Ventilating $\underset{-}{\overrightarrow{2}}$ Engineers, made on behalf of the U.S. Navy, it was $\vec{C}$ found that deterioration as measured by reduced output and accuracy in various psychomotor tests $\vec{\varphi}$ took place at 'effective' temperatures of $87 \mathrm{~F}$. and $94 \mathrm{~F}$. It is interesting to note that the tests used were all different from the one described in this report.

\section{Summary}

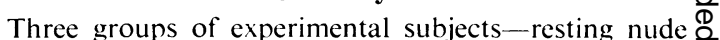
subjects given a short exposure to an "effective " tempera- $\overrightarrow{ }$ ture of $91 \mathrm{~F}$., clothed subjects after work in an environture of 91 . F., clothed subjects after work in an environ- $\frac{0}{3}$ subject during long exposure to an environment of 'effective' temperature 82 F.-96 F. both resting and 0 after work, all showed deterioration in the performance of a psychomotor co-ordination test.

The deterioration in performance was due to slowness of movement and in most of the subjects to inaccuracy in handling the balls.

\section{Acknowledgements}

We are indebted to Dr. E. Arnold Carmichael for his encouragement in this investigation and to Lady Frankau for bringing the co-ordination test to our notice: to $D$ Dr. Irwin for statistical advice and to Dr. Ladell for his co-operation in carrying out certain of the tests. The instrument was constructed by Major $\mathrm{H}$. C. Holden, $\mathrm{N}$ R. A. We also express our gratitude to the R.A.M.C. personnel for acting as subjects in the somewhat arduous $N$ tests.

\section{REFERENCES}

Work Performance of Young Men in Comfortable and Hot Atmospheres with Different Noise Levels (1942). Research Lab. Amer. Soc. Heating Vent. Eng.

Houghten, F. C., Teague, W. W.. and Miller W. E. (1926). J. Amer. Soc. heat. vent. Eng., 32, 315, 473. 